\title{
Evaluating Nursing Students' Perception toward Use of E-Portfolio as an Innovative Learning Strategy for Student Assessment
}

\author{
Asmaa Abdel Rahman Abdel Rahman*, Asmaa Hamdi Mohamed \\ Medical Surgical Nursing department, Faculty of Nursing, Ain Shams University, Cairo, Egypt \\ *Corresponding author: dr.asmaa.saleh@nursing.asu.edu.eg
}

\begin{abstract}
Portfolios have been advocated in nursing education to help student link theory and practice. E-portfolio has the advantage of allowing students to record, assess, and reflect upon their learning. Aim: This study aimed to evaluate nursing students' perception toward use of e-portfolio as an assessment tool through the following: (1) Assessment of nursing students' computer skills and knowledge about electronic portfolio. (2) Conducting theoretical and practical educational sessions about building e-portfolio. (3) Evaluating the nursing students' perceptions regarding use of electronic portfolios as an assessment tool. Study design: A descriptive exploratory research design was used to conduct this study. Setting: This study was conducted in classroom and computer laboratory at Faculty of Nursing, Ain Shams University, Cairo, Egypt. Subjects: A convenience sample of all nursing students $(\mathrm{n}=200)$ during the academic year 2015/2016 were recruited to participate in this study. Data collection tools: (1) Students' assessment questionnaire: to assess nursing students' previous experience regarding computer skills and previous knowledge about e-portfolio. (2) Self-administered students' perception questionnaire regarding use of e-portfolio. (3) E-portfolio Gen-software was used to allow students to build e-portfolio. (4) Self-administered students' opinionnaire regarding the theoretical and practical educational sessions. Results: Regarding overall perception related to e-portfolio, most of the students (92\%) reported that, "It is a good program and social media through which they can communicate easily with their teachers and colleagues and can share knowledge, ideas, opinions and clinical experiences with others". Nearly two thirds of the students $(66 \%)$ reported that, their experience with e-portfolio has been positive and the majority of them (82\%) stated that "creating e- portfolio was an interesting activity. Conclusion: The majority of the nursing students perceived the e-portfolio as a new way of assessment because it is creative, fun, interactive and stimulating. Recommendations: It is recommended to use the e-portfolio as an assessment tool for nursing students, in addition to conducting other researches to evaluate the effectiveness of e-portfolio as a learning tool.
\end{abstract}

Keywords: assessment, e-portfolio, learning, nursing students, perception

Cite This Article: Asmaa Abdel Rahman Abdel Rahman, and Asmaa Hamdi Mohamed, "Evaluating Nursing Students' Perception toward Use of E-Portfolio as an Innovative Learning Strategy for Student Assessment." American Journal of Nursing Research, vol. 5, no. 3 (2017): 86-95. doi: 10.12691/ajnr-5-3-3.

\section{Introduction}

Nowadays, the traditional methods are not enough for effective education of nursing students. The internet and other electronic technologies have had a deep impact on traditional methods of education and brought forth new methods for effective education. The use of an electronic portfolio (e-portfolio) is one of the newest methods of teaching [1].

E-Portfolio is defined as a regular and purposeful collection of electronic student's works that can be considered as the direct evidence of a learning journey and student's efforts, accomplishments and advancement throughout a period of time or course study [2]. This work may include artifacts such as projects, reports, presentations, assessments, videos, photos, hyperlinks, certificates, and other samples of work [3]. Artifacts are identified as products constructed as part of the learning experience [4].

E-portfolio has been known as 'the biggest innovation in educational technology [5] and one of the digital applications and tools that enable interaction, collaboration and sharing information, thus providing users with unprecedented learning experience [6]. In education a portfolio is usually a collection of information that informs the demonstration of learning that has occurred for student in a specific course or program of studies. A professional portfolio is a structured collection of different types of information and evidence that shows an individual's continuing professional development activities, experiences, competencies, professional achievement and goals [7].

E-portfolio demonstrates the skills students have learned in a particular class or program, particularly "soft skills" such as critical thinking and interpersonal skills that are difficult to quantify. Often used in place of a final 
exam, project, or paper. Students tend to be as motivated to create assessment portfolios as they are to complete a test or a project; their benefit is to pass the class or graduate from the program may include reflection component. It is suitable for students whose instructors are looking to test their achievement in certain academic areas; it's an assessment portfolio [4].

The main objectives of developing e-portfolio by students are to assist them to develop self-awareness; encourage continuous reflection of both clinical and theory topics; promote a lifelong learning philosophy; acquaint them of their own skills [8]; develop critical analysis, critical thinking skills and reflective learning abilities, and their clinical skills competencies [9].

Portfolio-based learning has several advantages; it enables learners to act and learn autonomously and allows them to assess their strengths and weaknesses, allows them to identify and meet their learning needs and build an education plan for the future [4]. E-portfolio allow for reflections on artifacts as well as how they match goals and standards, facilitate communicate with stakeholders (students, faculty, administrators, and employers), enhance information technology skills, and can be used as a tool to help career centers find jobs for students [10].

E-portfolios can be used as an assessment tool where students are required to show how they acquire knowledge and skills through the selection of and reflection on their learning activities. Teachers can monitor students' learning and assess their progress and achievement of learning outcomes [10]. It can be used as a formative and summative tool for course evaluation. As a formative evaluation tool, the e-portfolio can enhance student learning through providing a format for the student to describe their learning experiences via posting documents, videos, slideshows, and links to important materials used for learning development. It can also provide evidence about what the student has accomplished, and achieved through reflection [11]. The students have better opportunity to learn the materials, get more interested in furthering their education, and improve their communication skills [12].

As a summative evaluation tool, the e-portfolio can encapsulate what the student has learned. It also can provide a summary of achievements at specific points in time and can be used to evaluate student performance and attainment of course objectives [11]. The summative purpose of e-portfolio reflects on the development of personal assessment skills. Self assessment allows the students to develop skills that maximize their career potential and drives further learning [12].

\subsection{Significance of the Study}

Now with rapid changes in health field technologies in the age of communication and information, nurse educators have to prepare experts and skillful graduates for the demands of healthcare and increased complexity. Therefore; it is important to use modern electronic methods such as E-portfolios in nursing education and learning. This will help nurse student to become up to date, knowledgeable and skillful and this can lead to improvement of health in the society. Moreover, exploring novel approaches in practical nursing education can assist students in navigating the current knowledge explosion in health care, preparing them for careers that will require lifelong learning.

\subsection{Aim of the Study}

This study aimed to evaluate nursing students' perception toward use of e-portfolio as an assessment tool for second year medical surgical nursing students, faculty of nursing affiliated to Ain Shams University through the following:

1. Assessment of nursing students' computer skills and knowledge about electronic portfolio.

2. Conducting theoretical and practical educational sessions about building e-portfolio.

3. Evaluating the nursing students' perceptions regarding use of electronic portfolios as an assessment tool.

\subsection{Research Question}

What are the nursing students' perception regarding use of e-portfolio as an assessment tool?

\section{Methods}

\subsection{Research Design}

A descriptive exploratory research design was used to conduct this study.

\subsection{Setting}

This study was conducted in classroom and computer laboratory at Faculty of Nursing, Ain Shams University, Cairo, Egypt.

\subsection{Subject}

A convenience sample of all nursing students $(n=200)$ during the academic year 2015/2016 were recruited to participate in this study.

\subsection{Tools for Data Collection}

\subsubsection{Students' Assessment Questionnaire}

This questionnaire was developed in English language and designed by the researchers based on recent and related literature $[2,14]$ to collect data about the following:

a. Demographic characteristics of the students and includes two closed questions about age and gender.

b. Nursing students' previous experience regarding computer skills such as Microsoft word, power point presentation, internet and email skills, as well uploading different types of documents. This part consisted of six closed-ended questions requires the students to answer Yes or No.

c. Nursing students' knowledge about e-portfolio such as its meaning, contents, benefits, advantages, and if there is a previous experience about building eportfolio. This part had a combination of four openended questions and one close ended question. The time consuming to fill in this questionnaire was 5 minutes. 


\subsubsection{Self-administered Students' Perception} Questionnaire Regarding Use of E-portfolio:

This questionnaire was developed by the researchers based on the related literatures $[2,13,14]$ to assess nursing students' perception regarding use of e-portfolio. The questionnaire consisted of 29 statements requiring students to give opinion regarding every statement. The available responses ranged between agree, somewhat agree and disagree. These statements are concerned with students' perception regarding building e-portfolio (5 statements), sharing activities (4 statements), advantages of e-portfolio (9 statements), future usefulness of e-portfolio (4 statements), portfolio-Gen software (7 statements). Additional two open-ended questions were provided for students to ask them about the overall perception regarding e-portfolio as a student's assessment tool and the challenges they faced for building and use of e-portfolio. The questionnaire took about 20 minutes to give answers for all the questions.

The frequencies of responses for every statement were summed and its percentage was calculated.

\subsubsection{E-portfolio-Gen software}

Portfolio-Gen a free online service that allows users (teachers, students, and educators) to create online portfolios, to share their skills and achievements with peers and administrators and to showcase themselves and provide an opportunity for reflection and continued professional growth and development. It is easy for users to create and add portfolio pages, upload documents, insert photos and links, videos and add relative content to build a comprehensive online portfolio website.

The portfolio-Gen program was chosen by the researchers from different available e-portfolio software because it is free and open source software, has a simple interface with vertical menu contain 15 sections and dashboard, easy to use, easy to customize the design/layout, professional looking, ability to add and remove other colleagues, connecting users, ability to add and post comments, sharing of activity with other users, provide password protection of individual portfolio, ability to send and receive massages, provide daily statistics about number of visitors who viewed one's portfolio, students can display their interests and hobbies (Figure 1). In addition, the creators of the portfolioGen software are readily available and provide fast and friendly technical support for users, answer questions and willing to help. Students can reach any document on teacher's portfolio site without the need to print it. PortfolioGen is available at https://www.portfolioGen.com.

\subsubsection{Self-administered Students' Opinionnaire Regarding the Theoretical and Practical Educational Sessions}

This questionnaire is developed by the researchers to assess students' opinion regarding the theoretical and practical educational sessions such as researchers' presentation, the received guidance, feedback and technical support throughout the process of building the eportfolio and the handout given. It involved 10 statements requiring students to give responses for every statement on a three- point rating scale ranged between agree, somewhat agree and disagree. It took about 5 minutes to be filled out by the students. The frequencies of responses for every statement were summed and its percentage was calculated.

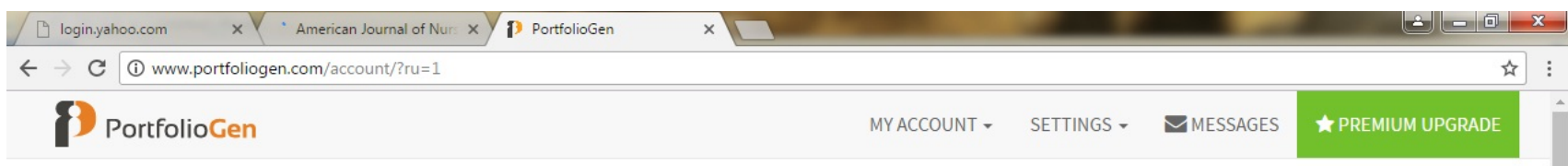

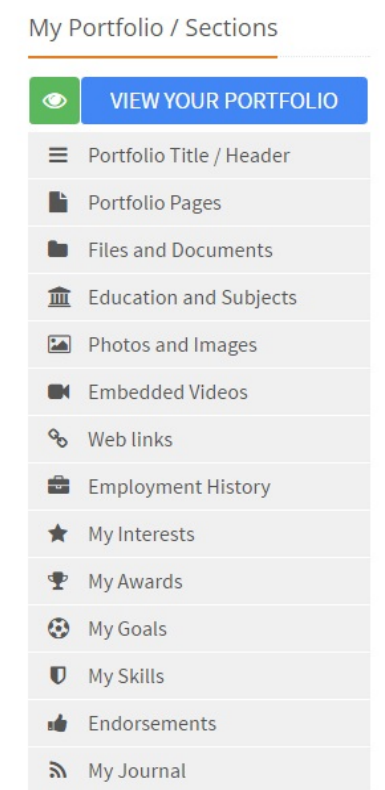

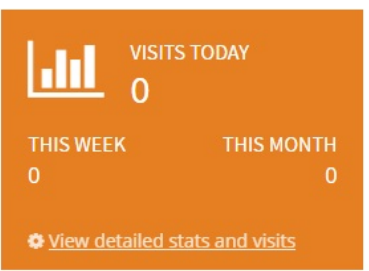

47 asmaa abdalrahman 2 MyProfile Ific III Faculty of Nursing/Ain Shams University $P$ Al Qahirah, Egypt Portfolio URL: www.portfoliogen.com/asmaa saleh Public Profile: www.portfoliogen.com/profile/asmaa-a-9d8d7b1.

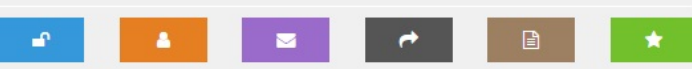

i What's New?
My Public Profile and Connections
Creating a Public Profile page is a great way to share information about yourself with the world without having to share your actual portfolio.
- Add your own separate content to your public page.
- Choose specific portfolio sections to include in your public page.
- Have visitors contact you via your message center. - Make connections with other PortfolioGen users.
- Turn your public profile page on and off at any time.
- Click to view a sample public profile page 


\subsection{Tools Validity and Reliability}

The tools were evaluated in terms of face and content validity by seven experts of medical surgical nursing. Some questions and items were omitted, rephrased, and then the final forms were developed. After verification of validity of the questionnaires by experts, reliability of the tools was tested. The reliability was achieved via Cronbach's alpha, Cronbach's alpha is a measure used to assess internal consistency of the questionnaire. In other words, it is how well a test consistently measures what it is supposed to measure. It was 0.90 for the students' assessment questionnaire, 0.82 for the students' perception questionnaire regarding use of E-portfolio and 0.79 for the students' opinionnaire regarding the theoretical and practical educational sessions.

\subsection{Pilot Study}

A pilot study was carried out on $10 \%$ of students in order to test the applicability of the study, ensure clarity of the study questionnaires, and to estimate the time needed for each tool. Based on the findings of the pilot study, no modifications were required. Students of the pilot study did not excluded from the study subjects.

\subsection{Ethical Considerations}

Permission to conduct the study was obtained from the Dean of the Faculty of Nursing before conducting the study and ethical approval was obtained from the Faculty's Research Ethics Committee. The aim of the study and the procedures were explained to the students to attain their cooperation. Oral consent was obtained from the students to ensure willingness to engage in the study. The researcher maintained anonymity and confidentiality of students.

\subsection{Procedure}

Procedure included three phases: preparatory phase, implementation phase and evaluation phase.

\subsubsection{Preparatory Phase}

This phase involved reviewing the Web sites and recent related literatures using books, articles, periodicals and magazines to develop the tools for data collection and choose the suitable e-portfolio software for use by the student.

\subsubsection{Implementation Phase}

- This phase started by explaining the nature and objective of the study as well as taking students oral approval to participate in the study prior to data collection.

- Data were collected from student in the period from October 2015 to May 2016.

- Students were asked to complete the students' assessment questionnaire to elicit their experiences regarding computer and software skills and background on e-portfolio.

- Theoretical educational session was conducted by one of the researcher for the students under study at the beginning of the medical surgical nursing course in the classroom to acquaint them about meaning of e-portfolio, aim of building e-portfolio, advantages of e-portfolio, process of building the eportfolio, artifacts required to complete their eportfolio in order to get their assessment, steps of registration and creating an account on portfolioGen site and how to login and logout the portfolioGen software. They also instructed about sections of portfolio-Gen software and how to deal through it. The session continues for 2 hours.

- The researchers conducted another practical sessions in the computer laboratory after dividing the student into ten groups to explain how to deal with the portfolio-Gen site. Each session continues for one hour.

- During these sessions the researcher shows the students how to make title for their portfolio, complete and edit their profile, how to add or upload profile picture, add or remove pages and web links on their portfolio site, upload files/documents or photos and video, also they learnt how to add and update their interests from the categories present already on portfolio-Gen software or add another categories they want. In addition they are learnt how to add contact type by which others can contact them either by adding email address or phone number. The researchers show the students how to add their colleagues in the contacts and allow them to view their portfolio, how to send and receive message, how to make their portfolio site public for others, method to change password and universal resource locator (URL) if they wish, how to view and get statistics about number of visitors to their site daily. Moreover, the students learnt methods of changing the theme/layout of their portfolio, how to edit colors, style and font of the portfolio, and how to change the background image. Finally the researcher explained how can students transform their e-portfolio to PDF format and print it or save it to their personal computer.

- Students were provided with a hard copy of the theoretical content as a guide to help them in the process of creating and developing e-portfolio. This hard copy contains screen shots of every section in the portfolio-Gen site and the steps required to proceed through it to complete every section.

- Students were required to register to e-portfolioGen software to complete their profile, and build eportfolio as part of their formative assessment in medical surgical nursing course.

- As a part of students' formative evaluation, each student was asked to upload their assigned activities such as developed Power Point presentation, pictures, video and web links about these activities and upload their certificates of the attended workshop and conference during the academic year. They were required to write their reflection on two clinical experience situations and assess their own performance (and highlight their expansion of knowledge).

- Ongoing technical support was provided by the researchers to the students as needed throughout the implementation phase. The students were allowed 
to send a message through portfolio-Gen site to the researchers for any inquiry.

- The researchers reviewed the evidences contained in every student's e-portfolios regularly to assess their progress, provide feedback through private personal message on the portfolio-Gen site and comment on the student's weakness and strengths. Students were encouraged to share activities and personal experiences and post comments to improve their communication.

- At the end of the academic year, the researchers checked the e-portfolio of every student. It was marked and the degree was added to the final score of the medical surgical nursing course degree.

\subsubsection{Evaluation Phase}

- At the end of the academic year (May 2016), seven months after building the e-portfolio, the students filled out the e-portfolio perception questionnaires to evaluate their perception about the use of eportfolio as an assessment tool during their learning activities. The questionnaire distributed to all students at the same time in the classroom. It took 15 to 20 minutes to complete the questionnaire.

\subsection{Data Analysis}

The responses to the statements were analyzed using SPSS version 20. The frequencies of each statement were computed by using frequency calculation option of SPSS program. The responses to the open-ended question was read and analyzed by the researchers. Students' responses to the open-ended questions were categorized, then the frequencies of the responds were calculated.

\section{Results}

The study results revealed that, more than half of students under study were females $(58.5 \%)$ and $(41.5 \%)$ were males, and they fall at the age group between 18-23 years old. All the students had previous experience about computer skills such as word processing, power point presentation skills and internet; while nearly have of them $(49 \%)$ had experience about uploading different types of documents. None of students had knowledge about the meaning, contents, benefits and advantages of e-portfolio.

By exploring the nursing students' perception regarding e-portfolio building, the results in Table 1 shows that less than half of nursing students under study $(45 \%, 49.5 \%)$ agreed that, building e-portfolio took a lot of time and increased the burden of their study respectively. Also, more than two thirds $(65 \%, 66 \%)$ of them agreed that, building e-portfolio require good computer skills and consider the design of layout of e-portfolio is an important issue respectively. Regarding perception of nursing students toward e-portfolio sharing activities, Table 2 revealed that, more than three quarters of students under study (78\%) agreed that, sharing activities helped them in building their own e- portfolio and more than two thirds of them $(68.5 \%)$ agreed that, sharing activities offered them chances to learn better from others and enabled them to share useful learning resources with their classmates.

Table 1. Nursing Students' Perception regarding Building of E-Portfolio

\begin{tabular}{|l|c|c|c|}
\hline \multicolumn{1}{|c|}{ Questionnaire items } & Agree (\%) & Somewhat agree (\%) & Disagree (\%) \\
\hline - It took me a lot of time to build the e-portfolio. & $90(45)$ & $81(40.5)$ & $29(14.5)$ \\
\hline - The e-portfolio increased the burden of my study. & $99(49.5)$ & $72(36)$ & $29(14.5)$ \\
\hline - By building my e-portfolio, I could complete the required learning goals. & $104(52)$ & $74(37)$ & $22(11)$ \\
\hline - Building the e-portfolio require good computer skills and artistic talent. & $130(65)$ & $56(28)$ & $14(7)$ \\
\hline - Designing the layout of my e- portfolio is an important issue. & $132(66)$ & $55(27.5)$ & $13(6.5)$ \\
\hline
\end{tabular}

Table 2. Nursing Students' Perception toward E-Portfolio Sharing Activities

\begin{tabular}{|l|c|c|c|}
\hline \multicolumn{1}{|c|}{ Questionnaire items } & Agree (\%) & Somewhat agree (\%) & Disagree (\%) \\
\hline - E-portfolio sharing activities helped me in building my own e- portfolio & $156(78)$ & $27(13.5)$ & $17(8.5)$ \\
\hline - E-portfolio sharing activities offered me chances to learn better from other classmates & $137(68.5)$ & $58(29)$ & $5(2.5)$ \\
\hline - E-portfolio enabled me to share useful learning resources with my classmates & $137(68.5)$ & $58(29)$ & $5(2.5)$ \\
\hline - E-portfolio sharing activities increased classmates' cooperative learning & $135(67.5)$ & $61(30.5)$ & $4(2)$ \\
\hline
\end{tabular}

Table 3. Nursing Students' Perception Related Advantages of E-Portfolio

\begin{tabular}{|c|c|c|c|}
\hline Questionnaire items & Agree (\%) & Somewhat agree $(\%)$ & Disagree (\%) \\
\hline - E-portfolio encouraged me to be independent learner. & $142(71)$ & $41(20.5)$ & $17(8.5)$ \\
\hline - E-portfolio encouraged me to assess my self-learning. & $145(72.5)$ & $41(20.5)$ & $14(7)$ \\
\hline - E-portfolio encouraged me to search information myself. & $141(70.5)$ & $49(24.5)$ & $10(5)$ \\
\hline - E-portfolio enabled me to improve my communication skills. & $149(74.5)$ & $41(20.5)$ & $10(5)$ \\
\hline - E-portfolio helped me to improve my computer skills. & $135(67.5)$ & $45(22.5)$ & $20(10)$ \\
\hline - E-portfolio enhanced my understanding of concepts and solving problems. & $107(53.5)$ & $74(37)$ & $19(9.5)$ \\
\hline - E-portfolio increased my willingness to learn actively. & $125(62.5)$ & $65(32.5)$ & $10(5)$ \\
\hline - E-portfolio helped me to access/ learn at anytime and anywhere. & $114(57)$ & $73(36.5)$ & $13(6.5)$ \\
\hline - E-portfolio helped me realize my strengths and weakness in nursing subject. & $113(56.5)$ & $70(35)$ & $17(8.5)$ \\
\hline
\end{tabular}


Table 4. Nursing Students' Perception Regarding Future Usefulness of E-Portfolio

\begin{tabular}{|c|c|c|c|}
\hline Questionnaire items & Agree (\%) & Somewhat agree $(\%)$ & Disagree (\%) \\
\hline - E-portfolio will be of great help to my future independent learning. & $135(67.5)$ & $48(24)$ & $17(8.5)$ \\
\hline - E-portfolio will be beneficial when applying for a job. & $125(62.5)$ & $64(32)$ & $11(5.5)$ \\
\hline - E-portfolio will be useful for my future life-long learning. & $102(51)$ & $69(34.5)$ & $29(14.5)$ \\
\hline - E-portfolio will help me for my career development. & $122(61)$ & $64(32)$ & $14(7)$ \\
\hline
\end{tabular}

Table 5. Nursing Students' Perception Regarding PortfolioGen Software

\begin{tabular}{|c|c|c|c|}
\hline Questionnaire items & Agree (\%) & Somewhat agree $(\%)$ & Disagree (\%) \\
\hline - It was easy and simple to use. & $105(52.5)$ & $82(41)$ & $13(6.5)$ \\
\hline - It lets me upload a variety of file formats (PDF, video, audio, picture and document). & $151(75.5)$ & $42(21)$ & $7(3.5)$ \\
\hline - It is a place to store papers, presentations, and other supporting material. & $170(85)$ & $30(15)$ & $0(0)$ \\
\hline - It enabled me to discuss my learning experience with my teachers. & $154(77)$ & $41(20.5)$ & $5(2.5)$ \\
\hline - It enabled me to share my learning experience with my colleagues. & $141(70.5)$ & $47(23.5)$ & $12(6)$ \\
\hline - It is characterized by sustainability (the ability to keep it after finishing the course/program). & $152(76)$ & $39(19.5)$ & $9(4.5)$ \\
\hline - It gave me the chance to reflect on my learning experience. & $111(55.5)$ & $78(39)$ & $11(5.5)$ \\
\hline
\end{tabular}

Table 6. Nursing Students' Perception Regarding Theoretical and Practical Educational Sessions

\begin{tabular}{|c|c|c|c|}
\hline Opinionnaire items & Agree (\%) & Somewhat agree $(\%)$ & Disagree (\%) \\
\hline $\begin{array}{l}\text { - The educational sessions provided me a clear explanation about e- } \\
\text { portfolio building and requirements. }\end{array}$ & $188(94)$ & $8(4)$ & $4(2)$ \\
\hline $\begin{array}{l}\text { - Offering me a previous student's portfolio samples gave me a better idea } \\
\text { about e-portfolios. }\end{array}$ & $156(78)$ & $30(15)$ & $14(7)$ \\
\hline - The handout is beneficial. & $183(91.5)$ & $17(8.5)$ & $0(0)$ \\
\hline $\begin{array}{l}\text { - The teachers' guidance given to me was effective in helping me create my } \\
\text { e-portfolio. }\end{array}$ & $170(85)$ & $25(12.5)$ & $5(2.5)$ \\
\hline $\begin{array}{l}\text { - The teachers' guidance helped me to understand why I need to compile an } \\
\text { e-portfolio. }\end{array}$ & $134(67)$ & $45(22.5)$ & $21(10.5)$ \\
\hline $\begin{array}{l}\text { - The teachers' guidance at the beginning of the process of building e- } \\
\text { portfolio was satisfactory. }\end{array}$ & $175(87.5)$ & $25(12.5)$ & $0(0)$ \\
\hline $\begin{array}{l}\text { - The teachers' guidance throughout the process of building e-portfolio was } \\
\text { satisfactory. }\end{array}$ & $163(81.5)$ & $37(18.5)$ & $0(0)$ \\
\hline - The teachers' guidance was at the level that I expected to receive. & $184(92)$ & $16(8)$ & $0(0)$ \\
\hline $\begin{array}{l}\text { - The frequent teacher's feedback about my e-portfolio was useful to inform } \\
\text { me about my progress. }\end{array}$ & $165(82.5)$ & $30(15)$ & $5(2.5)$ \\
\hline $\begin{array}{l}\text { - I received beneficial technical support from my teachers to build and use } \\
\text { the e-portfolio. }\end{array}$ & $117(58.5)$ & $62(31)$ & $21(10.5)$ \\
\hline
\end{tabular}

In relation to nursing students' perception regarding advantages of e-portfolio, Table 3 shows that, most of the students under study (95\%) agreed that, e-portfolio encouraged them to search information by themselves (70.5\% agree \& $24.5 \%$ somewhat agree), e-portfolio enabled them to learn communication skills $(74.5 \%$ agree $\& 20.5 \%$ somewhat agree) and e-portfolio increased their willingness to learn actively $(62.5 \%$ agree \& $32.5 \%$ somewhat agree). Concerning students' perception regarding future usefulness of e-portfolio, Table 4 reveals that, more than two thirds of them $(67.5 \%)$ agreed that, e-portfolio will be of great help to their future independent learning. However, $62.5 \%$ of them agreed that; e-portfolio will be beneficial when applying for a job and only 5.5\% of them disagreed about the same item.

In relation to nursing students' perception regarding PortfolioGen software, Table 5 shows that, the majority of them (85\%) agreed that, the PortfolioGen software is a place to store papers, presentations, and other supporting material. Moreover, $77 \%$ of them agreed that, it enabled them to discuss their learning experience with their teachers. Also $76 \%$ of them agreed that, it is characterized by sustainability. Table 6 shows that, most of nursing students (94\%) agreed that, they received clear explanation about building e-portfolio through the educational sessions. $92 \%$ of them reported that the teachers' guidance was at the level they expected to receive. Moreover, $91.5 \%$ of them agreed that, the handout given to them is beneficial. In addition, the majority of the students $(85 \%, 87.5 \% \& 82.5 \%)$ agreed that; the teachers' guidance helped them to create their eportfolio, the teachers' guidance at the beginning of the process of building e-portfolio was satisfactory and the frequent feedback from the teachers was useful to inform them about their progress respectively.

Regarding overall perception related to e-portfolio, analysis of the students' answers for the open-ended questions revealed that most of the students (92\%) reported that, "It is a good program and social media through which they can communicate easily with their teachers and colleagues and can share knowledge, ideas, opinions and clinical experiences with others". Nearly two thirds of the students (66\%) reported that, their experience with e-portfolio has been positive and the majority of 
them $(82 \%)$ stated that "creating e- portfolio was an interesting activity. Seventy one percent of the students reported that they are happy to acquire new skill, learn new software and try new learning and assessment method. Moreover, nearly half of the students (49\%) stated that, it is a good step taken by the faculty to allow them to learn and being evaluated through such method. Forty eight percent of the students were happy because they can keep important links for interesting Web pages to be able to reach it later. Ten percent of the students perceived this method as an interesting way that enables them to connect with other nurses all over the world. However, there was a negative comment by $29 \%$ of the nursing students who stated that, the experience of building e-portfolio was stressful and time-consuming at first during its creation.

On the other hand, concerning the challenges they faced during using the E-portfolio, it has been reported that; the technical issues hampered their use of the e-portfolio tool (27\%), unavailability of the internet access at all times was an obstacle $(32 \%)$, and nearly $42 \%$ of them reported that, the most difficult issue when they were requested expressing and reflect on their clinical experience through writing in English.

\section{Discussion}

The e-portfolio is a recent technology in nursing education that considered a way to engage nursing students in their learning and assessment. In the assessment portfolio, students are asked to perform real tasks that demonstrate meaningful application of essential knowledge and skills; they also required to explain what they did and did not learn in order to assess their own strengths and weaknesses as learners [15]. This study was carried out in order to evaluate nursing students' perception toward use of e-portfolio as an assessment tool.

The nursing students in the present study are skillful in using computer and nearly half of them were able to upload and download different types of documents, this may be because they acquired these skills through the social media sites as Facebook, Twitter and Whatsapp. While most of them have difficulty in dealing with email skills such as creating an account, sending and receiving messages and attached documents.

The nursing students of the current study didn't have any knowledge about e-portfolio. This may be owing to that, the nursing students weren't asked to perform electronic portfolio in their first year at the faculty, while the paper-based portfolio is one of the routine requirements for the nursing students in the first and second year. Also this is the first time to request from the second year students to build e-portfolio for the research purpose. This result is in agreement with Mok [16] who stated that, although all the students had been using different social networking sites such as Facebook to communicate with each other, they reported that, they did not have any experience on building their own electronic portfolios. Many of them lacked the technical knowledge or skills, which was indeed a prerequisite for developing their e-portfolios for the course.

\section{Perception related to building of e-portfolio:}

The majority of the students agreed that, the process of building e-portfolio took a lot of time which increased the burden of their study. These results may be due to the long menu of the portfolioGen software which contains 15 sections and they were required to complete their profile, upload their picture, their files and their documents, add contacts, change the layout and the background of their portfolio and transform their e-portfolio to PDF format to print it or save it to their personal computer which is considered too much work.

The these results agree with Gaba [3] who mentioned that the degree of familiarity and comfort a student had with internet technology was usually indicative of how easily he/she would adopt the e-portfolio structure. In addition, Elango, Jutti and Lee [14] stated that, slightly less than half of medical students stated that, portfolio adds to their workload and it is considered a burden for them. Also Naude and Moynihan, [17] stated that, the preexistent information communication and technology skills were limited amongst the nursing students, which may have influenced the perception of students who described the task as time consuming and difficult. Also, the same results are in the same line with Davis, Ponnamperuma, and Ker [18] who stated that, the medical students in their study reported that there was too much work in the portfolio process and that the process was time consuming.

The students in this study reported that, building e-portfolio requires good computer skills and artistic talents. This is because, students perform great efforts to show their talents in choosing and designing the layout and cover of the e-portfolio and in creating the required artifacts in a well presented view before submitting it for evaluation. This result is supported by Priscah, Ronald, and Tecla, [4] who stated that, e-portfolio is considered a way to show artistic abilities of nursing students as they created very personal and graphic covers or artifacts for their portfolios, they may use colour coded entries and dividers for different sections included in the e-portfolio.

Perception toward e-portfolio sharing activities:

Norazman and Rahman [19] reported that, students learn mostly from the interaction with their friends through giving and receiving feedbacks and group discussions created specifically for related topics. In the same context, the current study revealed that, a large number of the students agreed that, sharing activities helped them in building their e-portfolio and allowed them to learn from each other's by exchanging resources and hyperlinks that facilitate their learning. These results may be because the researchers asked the students to make their e-portfolio public/open for their classmates to enable them to receive and share ideas, thoughts, feedback and resources and to support each others. These make students more cooperative and spread a climate of competition between students. While the minority of the studied students didn't benefit from sharing activities to the same level due to time limitation that prevented them to find chances to share learning resources with their colleagues.

\section{Perception related to advantages of e-portfolio:}

Concerning the perception regarding the advantages of e-portfolio, most of the students under study stated that, e-portfolio encouraged them to be independent learners and search information by themselves. These results owe 
to the assigned duties and different activities requested from them by the teachers that made them search information independently to complete their tasks. The study students also reported that, e-portfolio enhanced their communication and computer skills. These results are due to the process of searching, uploading and sharing information through the internet that helped to increase their skills.

Slightly less than two thirds of nursing students under study reported that, e-portfolio increased their willingness to learn actively. These results may be because the e-portfolio gave them the opportunity to show their abilities and talents rather than to be passive learners during the traditional lectures in which the students just memorize the books or lecture notes. These results are in accordance with Malmir, et al., [1] who mentioned that, in the new assessment method by e-portfolio, the learner is active, so, the learning capability is at its peak by encouraging deep understanding, assessing and recognizing their achievements, showing their own skills, and become active independent learners.

Also one of the eminent advantages of e-portfolio that was reported by the nursing students is that, the eportfolio helped them to learn anytime and anywhere. This result may be due to their ability to reach the portfolioGen site through different ways such as mobile internet, computer laboratory in the faculty, internet at home or at students' dorms. These results are in agreement with Malmir, et al., [1] who stated that, by providing the required trainings and education via electronic portfolios, the students are free to learn the educational material at any time they desire.

Perception regarding future usefulness of e-portfolio:

In relation to the future usefulness of the e-portfolio, the present study revealed that half of students agreed that, e-portfolio will be useful for their future life-long learning and two thirds of them see that it is a good method to apply for job. These results may be because e-portfolio allowed students to keep their artifacts in one place and add the links of the useful learning sites and they can also upload their certificates and keep it on their e-portfolio to apply for job in the future. These results are in accordance with Pincombe et al., [20] they reported that, the students in their study were very proud of their final e-portfolio and look forward to use it as a mean to gain registration and as a showcase for future employment.

\section{Perception related PortfolioGen software use:}

As regard to the perception of students regarding PortfolioGen as software, half of students stated that, the software was easy and simple to use. Majority of them considered it as a place to store papers, presentations and other materials, and most of them stated that, the site allowed them to upload a variety of file formats, enabled them to discuss and share their learning with teachers and colleagues. In addition, more than half of nursing students reported that portfolioGen allowed them to reflect on their learning experiences. These results are in accordance with McNeill and Cram [21] who reported that, most of the respondents in their study agreed that an e-portfolio tool enabled sharing of learning with other students and $70.7 \%$ agreed that it supported a variety of upload formats.

These results are because the portfolioGen has a simple interface with menu that is easy to use, and enables the student to connect with each other, post comments, share their activities with themselves, and provide an opportunity for reflection and discussion with the teachers. Moreover, it is easy for users to upload documents, photos videos and links to build a comprehensive online portfolio website.

\section{Opinion regarding theoretical and practical}

\section{educational sessions:}

Chin-Yuan and Cheng-Chih, [22] stated that there are important factors should be considered when implementing e-portfolio such as providing students with clear guidance on constructing the e-portfolio, and how to use the e-portfolio. With respect to the theoretical and practical learning sessions about e-portfolio, the majority of the students stated that, they were provided with clear explanation about building e-portfolio and the teachers' guidance was at the level they expected to receive. Moreover, they stated that, they received enough support from the teachers at the beginning and throughout the process of creating the e-portfolio; this helped them to create it, and perform the required tasks.

These results may be due to the teachers' encouragement and appreciating the students' achievement together with providing support in several ways such as dividing them into small groups and allowing the hands-on for every student during the practical sessions in the computer lab, in addition to, the availability of the teachers to provide technical support for the students through the site by allowing them to send message about the problems facing them during the building of the e-portfolio. Also, providing them with handout showing the steps of building e-portfolio and list of the required activities was helpful and beneficial as reported by them. This interpretation is supported by Mok [16] who stated that, a technical staff members' support helped student in electronic portfolio building process. This support was in the form of user manuals, in-class demonstrations, and technical support hotlines.

The same results are in agreement with Fawn and McKenzie [23] who emphasized the importance of appropriate support, supervision, and feedback between the clinical facilitator and student nurse to complete each psychomotor competency skill and enter them into the e-portfolio. Moreover, the clinical facilitators have to check the e-portfolio of students regularly to view how well students are progressing, to help formative and summative assessment. Also, McMullan's [24] mentioned that, students pointed out that, for the e-portfolios to be successful, it is important for the students to receive feedback, clear guidelines, and support. McNeill and Cram [21] stated that, almost half of the respondents in their study agreed that, they had sufficient support to use the e-portfolio tool.

Also the results are similar to that of Nilson and Hopkins [9] who mentioned that, students were offered support both prior to implementing their e-portfolio during semester times in a number of ways including formal tuition, drop-in sessions and online help. Students were also provided with guides and online technical support via discussion forums within the learning management system, which were accessible throughout the semester. While, the same results are inconsistent with Elango, Jutti and Lee [14] they mentioned that, the majority of their study participants reported, they didn't receive adequate guidance from the faculty about portfolio writing. 
The students stated that, the ongoing assessment and feedback they received from the teachers' private messages via the portfolioGen software about their performance were very important because it facilitated their learning as it acquainted them with their progress and the level of achievement and encouraged them to complete the rest of their activities and the required learning goals. The students reported that, they got benefit from the samples of e-portfolio offered to them by the teachers. These results was supported by Gaba [3] who reported that, having and looking to examples and template of previous students' work can guide the new students in creation of their e-portfolio as it clarifies and facilitates students' meeting their learning objectives.

\section{Overall perception regarding to e-portfolio:}

The nursing students' experience with building e-portfolio was positive and interesting. This result agrees with Strivens et al. [25] whose study found that, the students' evaluation for e-portfolio was positive and suggested that, e-portfolios can be used successfully for both formative and summative assessment. Also Alexiou, and Paraskeva, [6] stated that, the success implementation of e-portfolio appear in the positive feedback from the students as they succeed to become engaged and enthusiastic during e-portfolio process.

Chin-Yuan and Cheng-Chih, [22] stated that nursing students displayed very positive attitudes overall when using the mobile e-portfolio, although there were some occasional stresses and technical difficulties. While, the same result is contradicting to those of Mok [16] who reported that, the whole students held rather negative opinions about developing their portfolios electronically.

The students also reported that, e-portfolio is convenient because they can access it from variant locations and it is a good method to document, achieve and catalog their activities and achievement overtime. Very little number of students is challenged by unavailability of the internet connection access all the time at their residence; however they overcome this problem by accessing the site through their mobile phones.

In the present study, asking about the challenges that faced the students, the students reported that, the process of reflection on their own work was very difficult. This can be attributed to that, the writing English language skills of nursing students are not perfect to enable them proceed in such activities, also may be because reflection is a new experience they never use before. This result is supported by Priscah, Ronald, \& Tecla, [4] who mentioned that lack of writing skills in portfolio development is considered one of the challenges in developing of e-portfolio. While this result was contradicted with Naude and Moynihan [17] who mentioned that 22 nursing students out of 32 reported that self reflection via activities such as evaluation of skills and setting learning goals was thought to be the most valuable aspect of the e-portfolio building process.

\section{Conclusion}

The majority of the nursing students perceived the e-portfolio as a new way of assessment because it is creative, fun, interactive and stimulating. They also liked the ongoing feedback and assessment from the teachers, collaboration and support from their classmates, exchange thoughts and reinforcement of their knowledge and understanding throughout the e-portfolio process.

\section{Recommendations}

According to the results of the current study, it is recommended to use the e-portfolio as an assessment tool for nursing students, in addition to conducting other researches to evaluate the effectiveness of e-portfolio as a learning tool and its effect on students' critical thinking and problem solving skills.

\section{References}

[1] Malmir, M., Zare, M., Sarikhani, R., Mansouri, V. and Salari, M., The Impact of Using E-Portfolio on Nursing Students, Future of Medical Education Journal, 6, 2. 9-12. 2016.

[2] Caner, M., Students views on using portfolio assessment in EFL writing courses, Anadolu University, Journal of Social Sciences, Vol. 10(1). 223-236. 2010.

[3] Gaba, A. Development and evaluation of an e-portfolio for use in a dietetic internship program, Procedia - Social and Behavioral Sciences, 174 (2015). 1151-1157. 2015.

[4] Priscah, J.M., Ronald, O.O., and Tecla, J.S., Portfolio development as a method of learning, assessment and evaluation in clinical nursing education in Kenya, International Journal of Scientific Research and Innovative Technology, Vol. 3 No. 6. 1-17. June. 2016

[5] Tzeng, Jeng-Yi, and Ssu-Han Chen, "College students' intentions to use e-portfolios: From the perspectives of career-commitment status and weblog-publication behaviours," British Journal of Educational Technology, 43.1 (2012). 163-176. 2012.

[6] Alexiou, A. and Paraskeva, F., Enhancing self-regulated learning skills through the implementation of an e-portfolio tool, Procedia Social and Behavioral Sciences, 2 (2010). 3048-3054. 2010.

[7] Andre, K. and Heartfield, M., Nursing and Midwifery Portfolios: Evidence of Continuing Competence, $2^{\text {nd }}$ ed., Churchill livingstone Elsevier, London, 2016, 3-4.

[8] Green, J., Wyllie, A., Jackson, D., Electronic portfolios in nursing education: A review of the literature, Nurse Education in Practice, 14(1). 1-5. September 2013.

[9] Nilson, C. \& Hopkins, M., Integrating PebblePad throughout an undergraduate nursing curriculum to build student nurses' beginning professional eportfolios, A case study from PebblePad's in 'Future Ready' conference on preparing and equipping learners for their journey. Discipline of Nursing, Murdoch University 1-8. 2016.

[10] Tubaishat, A. and Lansari, A., Using student e-portfolios to facilitate learning objective achievements in an outcome-based University, Journal of Information Technology Education: Innovations in Practice, Volume 12. 113-127. 2013.

[11] Josephsen, J., Electronic portfolios for distance learning: A Case from a nursing clinical course, International Journal of ePortfolio, Volume 2, Number 1. 15-27. 2012.

[12] Suckarieh, G., Implementing Electronic Portfolios for Learning and Assessment, University of Cincinnati, 1-8. 2010. Available http://ascpro0.ascweb.org/archives/cd/2010/paper/CEUE19900201 0.pdf. Accessed March 12, 2017.

[13] Yang, N.D., "Integrating Portfolios into Strategy-based Instruction for EFL college Students". IRAL, 41. 293-317. 2003.

[14] Elango, S., Jutti, R.C. and Lee, L.K., Portfolio as a learning tool: Students' perspective. Ann Acad Med Singapore, 34 (8). 511-514. September 2005.

[15] Emmett, D.J., Student engagement with an eportfolio: A case study of pre-service education students. A dissertation submitted to the faculty of education of the queensland university of technology in partial fulfillment of the requirements for the degree of doctor of education. 1-245. 2011. 
[16] Mok, J., As a student, I do think that the learning effectiveness of electronic portfolios depends, to quite a large extent, on the attitude of students!, The Electronic Journal of e-Learning, Volume 10 Issue 4. 407-416. 2012.

[17] Naude, M. and Moynihan, C. (2004).The implementation of an Electronic portfolio for nurses (Pilot 2). Perth: Graduate School of Business, Curtin University of Technology.

[18] Davis, M.H., Ponnamperuma, G.G., and Ker, J.S., Student perceptions of a portfolio assessment process, Medical Education, 43: 89-98. 2009.

[19] Norazman, S.F. and Rahman, A.A. (2014). Student Perceptions on the Implementation of E-portfolio System, Journal of Information Systems Research and Innovation, Pp. 18-24. Available at http://seminar.utmspace.edu.my/jisri/. Accessed April 20, 2017.

[20] Pincombe, J., McKellar, L., Weise, M., Grinter, E. and Beresford, G., ePortfolio in midwifery practice: "The way of the future", Women Birth, 1-9. 2009.
[21] McNeill, M. and Cram, A., Evaluating e-portfolios for university learning: Challenges and opportunities, In G. Williams, P. Statham, N. Brown \& B. Cleland (Eds.), Changing Demands, Changing Directions. Proceedings ascilite hobart, 2011, 862-873.

[22] Chin-Yuan, L., \& Cheng-Chih, W.U., Promoting nursing students' clinical learning through a mobile e-Portfolio. CIN: Computers, Informatics, Nursing, vol. 34, No. 11. 535-543. November 2016.

[23] Fawns, T. and McKenzie, K., How to ensure e-portfolios are a valuable resource to students' learning, Nursing Times, 106(30), 21-23. 2010.

[24] McMullan, M., Using portfolios for clinical practice learning and assessment: The pre-registration nursing student's perspective. Nurse Education Today, 28, 873-879. 2008.

[25] Strivens, J., Baume, D., Grant, S., Owen, C., Ward, R., and Nicol, D., The role of e-portfolios in formative and summative assessment: Report of the JISC-funded study. Centre for Recording Achievement and Bristol: Joint Information Systems Committee. 2009. 